\title{
Psicologia Escolar: tendências para o século XXI
}

\author{
Eliana Bhering e Lísia Míchels \\ Curso de Psicologia - Centro de Ciências de Saúde - UNIVALI ${ }^{1}$
}

\begin{abstract}
Resumo
Este artigo busca refletir sobre aspectos que influenciam e determinam a atuação do psicólogo escolar exemplificado a partir de uma situação atual de violência que tem ocorrido com freqüiência nas escolas brasileiras e de outros países. A partir dessa reflexão, o presente trabalho visa apontar algumas características inerentes à ação do psicólogo escolar que possam vir a facilitar a concretização das ações psicológicas em instituições educativas.

Palavras-chave: psicologia escolar, atuação, escola.
\end{abstract}

\section{School Psychology: tendencies for the XXI century}

\section{Summary}

The article aims to reflect upon aspects that influence and determine the educational psychologist's scope of action. The discussion takes brazilian and other nationalities schools' current situations of violence as an example for effective use of the psychology expertise and knowledge. The discussion is built up towards highlighting intrinsic characteristics of the psychologists in educational settings.

Key-words: school psychology; scope of action; school.

Temos assistido ultimamente e repetidas vezes na televisão como "headline", a violência nas escolas. É importante notar que este não é um problema tipicamente brasileiro como muitos de nós poderíamos pensar ou apressar para concluir. Ao contrário, escolas de países desenvolvidos e que portanto poderíamos pensar que não têm os problemas sociais que nós tão visivelmente temos, tem apresentado um quadro extremamente complexo, preocupante e semelhante ao nosso. O problema parece ultrapassar dimensões econômico-sociais.

De imediato, o que vem à mente ao ouvirmos tal notícia passa por aspectos como insegurança e total despreparo em decorrência da pressão que nossas famílias têm vivido pela crise mundial do desemprego. As especulações sobre os ocorridos apontam para o armamento de crianças, jovens e jovens adultos. Estamos assistindo a isso diariamente: as crianças estão tendo fácil acesso a instrumentos de ataque, e como se isso não bastasse, às armas de fogo. Dizem os próprios portadores, que estas são utilizadas como instrumentos de proteção e defesa. Ora, o que está nos faltando? Ou melhor, o que está levando nossas crianças a concluir que agora precisam deste tipo de ação para se protegerem física, social, moral e psicologicamente? E ainda, protegê-los assim nas escolas?

As teorias psicológicas que temos, hoje em dia, a nossa disposição nos dão indicações sobre como formar cidadãos ativos e produtivos para o futuro equilibrado de nossas sociedades. Teóricos como Piaget e Vygotsky, apontam-nos para a capacidade de aprendizagem da criança e situações propícias para o desenvolvimento integral da mesma, no sentido de dar a devida oportunidade para que suas habilidades sejam consideradas em todas as etapas de seu crescimento. Para Piaget

\footnotetext{
${ }^{1}$ Endereço para correspondência: Núcleo de Pesquisa de Psicologia, Rua Uruguai 458 CP 360, Itajaí CEP 88.302-202 Santa Catarina - Tel: (Oxx47) 341-7679 - e-mail: ebhering@mbox1.univali.rct-sc.br Fax: (Oxx47)-341-760.
} 
(Meadow, 1996), a interação da criança com o meio ambiente é vital para seu desenvolvimento. Para Vygotsky (Meadow, 1996), o papel do adulto neste processo de aquisição de habilidades e conteúdos, é então visto através da idéia de andaimes "humanos", isto é, este apóia e respeita o desenvolvimento da criança enfatizando a participação ativa do mesmo em todo processo, ao invés de fazer por ela. O adulto apresenta-se, ouve, planeja, prepara (o ambiente), auxilia no fazer, e revê junto com elas atividades experienciadas para fazer da aprendizagem algo significativo. Essas teorias nos alertam para a aprendizagem ativa e suas implicações na educação.

No âmbito social da educação escolar, estudos sobre envolvimento de comunidades, famílias e pais no processo escolar mostram-nos que, além de acompanhar o entendimento das teorias psicológicas que valorizam as experiências vividas em outros ambientes que fazem parte da vida de qualquer criança (Bronfenbrenner, 1979; Freire et al, 1988), os resultados de ações conjuntas são positivos e mais "lucrativos" para todas as partes envolvidas (Epstein, 1982, 1991; Tizard et ai, 1982, Freire et al, 1988, Bhering e Siraj-Blatchford, 1999). Além destes estudos, a tendência atual de trabalhos comunitários passa de uma visão assistencialista para uma abordagem mais participativa onde visamos o envolvimento ativo de pessoas na comunidade para a liderança e desenvolvimento de projetos (agentes sociais, de saúde etc). O importante é que todos adquiram a possibilidade (e o direito) de fazer e construir suas próprias vidas de maneira digna e saudável através de iniciativas que fomentam e valorizam a capacidade e potencialidade do indivíduo.

A influência da Psicologia nas salas de aula é de extrema importância. Notamos hoje, que a ênfase da educação formal, do currículo, da Lei de Diretrizes e Bases e dos Parâmetros Curriculares Nacionais parte da abordagem que defende uma pedagogia centrada na criança e não mais na figura do professor como detentor do conhecimento ou do currículo que deve ser cumprido à risca até ao final sem nos atentarmos para o sucesso da criança. Queremos nos mobilizar para o sucesso da criança, pois todas elas têm a capacidade para aprender. Nunes, Schliemann e Carraher (1993) nos mostraram isso, quando apresentaram os resultados de sua pesquisa. Meninos de rua conseguem completar complicados cálculos matemáticos em situações informais, mas quando chegam na escola fracassam!! Machado (1994) aponta para as dificuldades tanto de ensinar quanto de aprender. Em seu estudo demonstrou que diagnósticos psicológicos também são capazes de produzir "alunos especiais", que por sua vez, passam a se comportar e ocupar estes lugares especiais. A mensagem parece estar dada: a criança aprende, apesar de situações e condições físicas, psicológicas e sociais muitas vezes comprometidas e precárias.

Estamos acompanhando o Programa Acelera Brasil que tem como objetivo principal preparar as crianças que não estão nas séries correspondentes à sua idade cronológica (correção do fluxo escolar) para avançar para as séries correspondentes, mas sobretudo, visa resgatar nos professores o real significado de ser professor. De acordo com Oliveira (1998), o aluno sempre aprende, mas o problema está em como fomentamos a aprendizagem nas salas de aula e na escola. Segundo o referido autor, não respeitamos os alunos de maneira a capitalizar a sua capacidade para. aprendizagem e para o desenvolvimento das suas habilidades sociais. Oliveira afirma que:

"O papel do professor é deslocado. Seu desafio principal não é dar aulas ou cumprir o programa - é fazer o aluno dar certo. O material de ensino cuida do programa. O professor cuida para que o aluno aprenda o material de ensino e tenha prazer em ler e estudar. O professor aprende a trabalhar com indivíduos, pequenos grupos e a turma inteira, prestando atenção no crescimento 
de cada aluno" (p. 71-72).

Promover e alcançar o sucesso escolar dos nossos alunos brasileiros é batalha árdua. Temos uma situação multiproblemática e portanto difícil de ser destrinchada em seus vários aspectos e características para a sua devida apreciação e respectiva ação para cada situação individual. Entretanto, devemos reconhecer os esforços das secretarias da educação (municipais e estaduais) quando promovem cursos de treinamento e atualização para professores realçando a importância da aprendizagem enquanto professores paralelamente à aprendizagem dos alunos. Reconhecemos também as diversas iniciativas traduzi das em projetos locais espalhados pelo Brasil que têm alcançado seus objetivos de promover a criança e seu crescimento/desenvolvimento saudável. Mas ainda nos falta reconhecer, que o objetivo principal é promover chances justas e adequadas para que a criança cresça e realmente se torne um cidadão digno, participante e produtivo.

Acompanhando toda essa evolução e produção dos conhecimentos científicos e os avanços dos projetos, programas, tendências e teorias educativos, a atuação do psicólogo escolar tem sido valiosa. Produzimos conhecimento que atuam diretamente nas escolas. Desenvolvemos diversas práticas para abordar os aspectos (inesperados e específicos) surgidos nos ambientes educativos. Complementamos ações multidisciplinares que visam o desenvolvimento integral do cidadão e de sua comunidade. Promovemos saúde pública que resultam das nossas ações particulares. Apesar de ainda não reconhecidos pelo sistema nacional de educação (Del Prette, 1999), a demanda para nossos serviços ultrapassa o estado de latência. É notória a necessidade e a urgência do ingresso do psicólogo não somente nas escolas como também em todas as instâncias que lidam com a infância, adolescência, família, comunidade, desenvolvimento social e a educação (incluindo aqui o acesso à famílias carentes).

A literatura sobre a atuação do psicólogo escolar é ampla no sentido de contemplar as diversas possibilidades do psicólogo em instituições educativas. Guzzo (1998) em sua cartilha "Psicólogo Escolar: quem é ele?" põe de maneira simples e clara o que fazemos, onde trabalhamos e alguns exemplos do que fazemos. Wechsler e Guzzo (1993) nos mostram (entre outras coisas) onde verdadeiramente estamos e o que fazemos (ou o que estamos podendo fazer) aqui no Brasil (talvez principalmente em São Paulo). Elas ressaltam que apesar dos grandes avanços na compreensão do nosso papel e da teoria, a nossa prática deixa a desejar em decorrência de situações que fogem do nosso domínio (como por exemplo, a nossa presença nas escolas). Del Prette (1999) completa apontando as falhas da nossa LDB em não contemplar que o psicólogo é o profissional adequado para atender às novas leis que regem a nossa educação. Nossas tarefas passam por assessorar, analisar e participar de projeto pedagógico, instrumentos de avaliação, atividades complementares, alternativas de restruturação funcional, interações em sala de aula, elaborar e desenvolver programas, e fazer diagnóstico e encaminhameqto de problemas relacionados a queixas escolares (Del Prette, 1999).

O nosso quadro atual, principalmente em escolas públicas de grandes centros (São Paulo, Rio de Janeiro, e Belo Horizonte como, recentemente, mostrado na mídia brasileira), parece estar indicando que nossas funções ampliem-se para um atendimento de casos que pertencem e partem tipicamente de problemas (de acordo com Del Prette op cit, queixas) escolares. Os motivos da violência anunciados por colegas (dos agressores) presentes nas cenas de violência nas escolas brasileiras passam por má compreensão de regras, avaliações parciais, relacionamentos confusos 
(incluindo com professores, orientadores e diretores), formação de gangues, competições (negativas) em jogos, gozações, preconceitos, e até questões de ordens pessoais. Ora, tais reações requerem atendimento por profissionais da Psicologia dentro e fora da escola. Em situação de Estágio Supervisionado de Psicologia Escolar no Estado de Santa Catarina, temos trabalhado repetidamente com a demanda de atendimento dentro da escola de casos como violência, comportamentos não aceitáveis que os professores não conseguem abordar efetivamente, angústias de crianças vítimas de violência e opressão no lar e na escola, frustrações, não acompanhamentos das tarefas escolares e etc. São situações típicas de atendimento psicológico, pois estas reações refletem a e na vida pessoal e portanto psicológica do indivíduo.

Desta forma, atentamos para os fatores educacionais que o nosso sistema se refere (métodos voltados para um ensino centrado na criança valorizando seus motivos, capacidade e participação), aos princípios que regem a atuação do Psicólogo Escolar (que segundo Coll, (1996, p.18) devemos prestar atenção aos "processos de mudança comportamental provocados ou induzidos nas pessoas, como resultado de sua participação em atividades educativas") e à forma de atuação do psicólogo em geral. Ao psicólogo, cabe a tarefa de ajudar pessoas a se sentirem, conhecerem e estarem melhor na sua vida. Cabe aos psicólogos, promover a saúde do indivíduo instrumentalizando-o para o reconhecimento e/ou descoberta de habilidades pessoais que o mobiliza para a vida, e preparar os ambientes para receber aqueles em crescimento e propiciá-los um ambiente instigante para a aprendizagem (e não um ambiente potencialmente ameaçador).

Este artigo não é um protesto a esta situação de falta de profissionais da área de Psicologia. É mais do que isto. É um alerta à comunidade sobre a Psicologia nas escolas (e da vida). Quando é que vão realmente atender a demanda social? Quando é que realmente vão reconhecer o estado psicológico do nosso público escolar formal e informal e suas famílias? Quando é que vamos compreender que a escola ultrapassa o ser somente para dar lugar à transmissão do conhecimento? Quando é que vamos admitir que, para além da discrepância social, o sucesso das crianças está intrinsicamente ligado ao estado psicológico das mesmas (traduzidos em auto-estima, autonomia, valorização da cultura do outro, preconceito, gozação etc) e de suas famílias? É na verdade uma questão de clareza: o professor começa a perceber que o aluno é a parte mais importante do processo ensino-aprendizagem, mas sua concentração deve permanecer também nos vários conteúdos do currículo. Pode ser também uma questão de tempo; por exemplo: quando é que o professor pode atender as demandas psicológicas de seus alunos? Estará ele preparado só a partir da compreensão de que educação é mais do que os conteúdos e habilidades a serem apreendidos e desenvolvidas respectivamente?

Nos Estados Unidos, a discussão ultrapassa a compreensão e prática dos avanços das teorias e práticas educativas e psicológicas para a compreensão sobre quem e o que poderíamos culpar pelas recentes atitudes dos jovens americanos. Serão os pais? Serão os órgãos locais responsáveis pela educação e saúde da população? Será o Estado e a Federação (segundo Bronfenbrenner (1996) o macrosistema)? Qual a prática preventiva que falhou? Quais as estratégias que não estamos praticando? Será a influência da Internet e autores dos programas violentos? Toda a comunidade está sob investigação. A comunidade científica e profissional está convidada a participar de debates e a apresentar seus estudos, suas estratégias e programas. As prioridades começam a se voltar para espaços/temas/profissionais para além daqueles que pertencem à escola.

Aproveitando esta reflexão dos norte-americanos sobre suas ações (constantemente em 
debate em revistas como a Time e na televisão, especialmente na CNN), não precisamos ir tão longe ainda para saber que precisamos desenvolver estratégias e estabelecer prioridades para não só entrarmos nas escolas como também para atender as demandas oriundas daquele ambiente, como ainda compreendermos a parcela individual de cada envolvido neste processo de deterioração dos ambientes escolares. Nossas estratégias devem incluir o aproveitamento do espaço (físico e subjetivo) escolar para atendimento das demandas, incluindo ações práticas e de baixo custo (como abertura para as práticas preparadas pelos psicólogos) para serem incluídas na rotina das crianças, da sala de aula, do professor, da equipe pedagógica e da escola como um todo. Nossa ação é urgente para novas estratégias e prioridades para cruzarmos o século XXI privilegiando, tanto os aspectos cognitivos e físicos como os sociais e emocionais dos estudantes.

Para privilegiar o indivíduo em formação em seu desenvolvimento integral e promover a compreensão mútua de que o objetivo principal é criar um ambiente propício para aprendizagem significativa para os nossos jovens, nossas ações devem contemplar aspectos pessoais do estudante e de seus grupos e considerar as características da situação que indicariam como as ações poderiam ser incorporadas às ações típicas da escola. Podemos indicar dois grupos, respectivamente, como descritos a seguir:

a. • a identidade cultural (social) dos alunos;

- a aprendizagem ativa;

- casos individuais que desencadeiam reações nos demais;

- reações de grupos etários diferentes;

- reações dos professores, pais e outros adultos;

- interações entre adultos e crianças, e entre crianças;

- diferentes atividades para diferentes grupos de estudantes e professores.

b. - fatores e recursos ambientais;

- a identidade cultural da escola;

- equipes multidisciplinares disponíveis;

- praticidade, relevância e viabilidade das ações;

- as atividades escolares (currículo);

- a provisoriedade das ações propostas (uma vez que a revisão e avaliação das ações e novas tendências na área da Psicologia Educacional e Escolar devem ser constantemente feitas);

- e principalmente a real demanda produzida e refletida na escola.

\section{Referências}

Bhering, E. e Siraj-Blatchford, I (1999). Envolvimento de Pais: um modelo de troca e colaboração. Cadernos de Pesquisa, V 01. 106, pp. 191216, Março 99. Fundação Carlos Chagas, SP.

Bronfenbrener, U. (1996). A Ecologia do Desenvolvimento Humano. Artes Médicas: Porto Alegre, SP.

Coll, C. (1996). Psicologia e Educação: Aproximação aos Objetivos e Conteúdos da Psicologia da Educação. In Coll, C.; Palacios, J. e Marchesi, A. (Org.) Desenvolvimento Psicológico e Educação - Psicologia da Educação. Vol2 - 1996. Artes Médicas: Porto Alegre.

Del Prette, Z.A.P. (1999). Psicologia, Educação e LDB: novos desafios para velhas questões? In Guzzo, R.S.L. (Org.) Psicologia Escolar: LDB e Educação Hoje. Editora Alínea, Campinas SP.

Epstein, J. (1982). Parent Involvement: A Survey of Teachers'Practices - The Elementary School Journal, V. 83, no. 2, pp. 85-102. 
Epstein, J.L. e Dauber, S.L. (1991). School Programs and Teachers Practices of Parent Involvement in Innercity Elementary and Middle Schools. The Elementary School Journal, 91, 3, pp.289-305.

Freire, P.; Nogueira A. e Mazza, D. (1988). Na Escola que Fazemos. Uma reflexão interdisciplinar em educação popular. Vozes. Petrópolis, RJ.

Guzzo, R.S.L. (1998). Psicólogo Escolar: Quem é ele? PUC-Campinas, Editora Alínea (Campinas).

Machado, A.M. (1994). Crianças de Classe Especial: efeitos do encontro da saúde com a educação. Casa do Psicólogo. São Paulo.

Meadow, S. (1996). Parenting Behaviour and Children 's Cognitive Development. Psychology Press East Sussex UK

Nunes, T.; Schliemann, A.D. e Carraher, D.W. (1993). Street Mathmatics and school mathmatics. New York: Cambridge University Press.

Oliveira, J.B.A. (1998). A Pedagogia do Sucesso: uma estratégia política para corrigir o fluxo escolar e vencer a cultura da repetência. Instituto Ayrton Senna, SP.

Tizard, B.; Hewinson, L. e Schofield, W.N. (1982). Collaboration Between Teachers and Parents in Assisting Children' s Reading. British Journal of Educational Psychology, 52, pp. 1-15.

Wechsler, S.; Guzzo, R.S.L. (1993). Novos Caminhos da Psicologia Escolar Brasileira. Estudos de Psicologia, 10(3): 21-40.

Recebido: 18/05/99

Aprovado: 28/08/99 